\title{
Practical Skills of Dentists Regarding Medical Conditions Assessment in Dental Offices of A Tertiary Care Dental Hospital, Karachi
}

\author{
Marium Zaheer ${ }^{1}$ \\ Arsala Urooj ${ }^{2}$ \\ Salik Rasool ${ }^{3}$ \\ Waqas Ahmed Farooqi ${ }^{4}$ \\ Umer Irfan ${ }^{5}$
}

\author{
BDS, MDS \\ BDS, MDS \\ BDS, MDSc, M.Phil, Cert. OPOM \\ MSc \\ BDS, MSc
}

OBJECTIVE: The objective of this study was to identify the practical skills of dentist in terms of history taking, examination and advising laboratory investigations for systemic diseases in dental OPDs of Dow University of Health Sciences.

METHODOLOGY: The study was conducted at all three dental colleges of Dow University of Health Sciences; from May 2016 to June 2016 to a sample of dental students and dental faculty members by convenience sampling. This was a cross sectional study. Total 450 surveys forms were distributed among faculty members, post graduates and undergraduates dental students. The data was analyzed on IBM SPSS version 24.0 Statistical association were performed using Chi-square test.

RESULT: Most of the participants of the study $(n=246,78.1 \%)$ reported taking complete medical history at first visit. The medical examination skills of participants were satisfactory. The practice of lab investigation for systemic diseases was also satisfactory.

CONCLUSIONS: It was concluded that practice of medical history taking, medical examination and lab investigations by dental professionals of DUHS was found to be adequate. Dentist skills were not dependent on gender, designation and basic or clinical sciences.

Key Words: medical assessment, investigatory skills, medical screening

HOW TO CITE: Zaheer M, Urooj A, Rasool S, Farooqi WA, Irfan U. Practical skills of dentists regarding medical conditions assessment in dental offices of a tertiary care dental hospital, karachi. J Pak Dent Assoc 2018;27(2):71-75. DOI: https://doi.org/10.25301/JPDA.272.71

Received: 09 November, 2017, Accepted: 09 March, 2018

\section{INTRODUCTION}

$\mathrm{O}$ ral cavity represents an overall health status of an individual. ${ }^{1} \mathrm{An}$ important component of any health care program is prevention from disease and early identification of individuals who are at increased risk of disease development. The early identification of diseased individuals reduces the morbidity and mortality rate and economic burden of the country. The part of dentist is

1. Assistant Professor, Deptarment of Oral Pathology, Dr.Ishratul Ebad Khan Institute of Oral Health Sciences, Dow University of Health Sciences.

2. Assistant Professor, Department of Oral Pathology, Dr.Ishratul Ebad Khan Institute of Oral Health Sciences, Dow University of Health Sciences.

3. Associate Professor, Department of Oral Pathology, Dow International Dental College Dow University of Health Sciences.

4. Lecturer Department of Research, Dow University of Health Sciences.

5. MSc trainee Department of Oral Pathology, Dow International Dental College

Dow University of Health Sciences.

Corresponding author: "Dr. Marium Zaheer” < marium.zaheer@duhs.edu.pk > imperative in providing the service of disease control, in terms of screening the dental patient at chairside by practicing proper history taking and examination skills. ${ }^{1}$

A dentist must be aware of complete medical condition of his/her patient before performing dental treatment or prescribing any medications. ${ }^{2}$ Therefore, it is crucial that dentists, residents and students working in dental OPDs take complete history of dental patient. Patients attending dental outpatient department would easily be screened for systemic diseases. Worldwide many studies have been conducted to identify most frequently screened systemic conditions in dental offices, which includes hypertension ${ }^{3}$ and other risk factors for heart diseases ${ }^{4}$, hepatitis, diabetes ${ }^{5,6}$, allergies, peptic ulcer and rheumatoid arthritis in dental office. Type II Diabetes mellitus ${ }^{6}$ and hypertension are among the most afflicted global health problems which remains insidious 
until complication arises, such as vascular damage, angina or myocardial infarction. ${ }^{7}$ In a research by Glick et al, it is suggested that future research must focus on screening risk factors of cardiovascular diseases, chronic obstructive pulmonary diseases, diabetes, or kidney disease. ${ }^{4}$ From strategic point of view dentist could be an important resource for integrated health care delivery to the patients who present in dental clinics with systemic disease. Recent studies suggest that majority of dentists give importance and show willingness to conduct medical history. ${ }^{8}$

There seems a dearth in literature review to report the practice of medical screening in dental settings in Pakistan, as well as the extent to which the dentists can broaden their horizon of knowledge and practice to screen dental patients for medical condition at chair side and refer them to concerned specialists. Therefore, we designed this study to identify the practical skills of dentist in terms of history taking, examination and advising laboratory investigations for systemic diseases in dental OPDs of Dow University of Health Sciences.

\section{METHODOLOGY}

The study was conducted in all three dental colleges \{Dr. Ishrat-ul-Ebad Khan Institute of Oral health sciences (DIKIOHS), Dow International Dental College (DIDC) and Dow Dental College (DDC) $\}$ of Dow university of Health Sciences. The study was conducted from May 2016 to June 2016. A study sample was collected from participants who were present at the day of survey by convenience sampling. The students of third and final year BDS, house officers (attending dental departments for the last three months period), all post graduate trainees (MDS, MSc basic and clinical dental sciences, and FCPS clinical dental sciences) and dental faculty members were included. The faculty members comprise of lecturers, assistant professors, associate professors and professors. The dentists (post graduate trainees and faculty members) who were in basic dental sciences and reported to have dental practice in evening hours, thus have patients' interaction were included. First and second year BDS students were excluded. The participants having no interaction with patients even in evening dental practice were also excluded.

In our cross sectional study, total 450 survey forms with written consent were distributed in offices and dental OPDs. The forms were collected on the same day. The dentists were divided into two main domains that were basic dental sciences (oral pathology, oral biology, community dentistry and dental materials) and clinical sciences (operative dentistry, oral surgery, orthodontics, prosthodontics, oral medicine, periodontology).
Total 14 questions were included in questionnaire about chair side history taking, medical examination and advising laboratory investigations for the common systemic diseases.

All questions in a history taking practice that focus on the evaluation of medical condition were gathered and scored and a term history taking skill (HTS) was designated (scoring method is further described in section of statistical analysis of this paper). The HTS included questions about following systemic diseases: diabetes mellitus, hypertension, hepatitis A, B and C, gout, arthritis, peptic ulcer, anemia, tuberculosis, asthma, typhoid and drug allergies and question related to pregnancy and/or lactation from female of child bearing age. The next section of survey form comprised of medical examination skills (ES) of dentists. It includes the examination of patient conjunctiva, sclera and tongue for suspected anemia and jaundice. Furthermore, question regarding measurement of blood pressure of every patient was asked. The next part of survey form consisted of question about investigatory skills (IS) of dentist by asking what laboratory tests were advised for anemia, diabetes mellitus, arthritis, gout, peptic ulcer and tuberculosis from their dental patients with suspicion of above mentioned diseases.

Out of four hundred and eight filled survey forms, 87 forms were discarded due to insufficient data. The majority of participants ( $\mathrm{n}=315,98.1 \%)$ had patient interaction either in dental OPD's during clinical posting or in evening dental clinics. Six forms were discarded due to no interaction with patient.

\section{Statistical Analysis}

The data was analyzed on IBM SPSS version 24.0 and the results were presented as frequency and percentages for all skills (HTS, ES, IS), demographics like gender, designation and sciences except age presented as mean \pm SD. Satisfactory or unsatisfactory skills were created for history, examination and investigation. Initially dichotomous variable of satisfaction was created, the responses 'often' and 'always' were considered as having satisfactory skill and the response 'rarely' was considered as unsatisfactory skill. These skills score and dichotomous variable were created on 50\% score. For investigation skills, 3 or more positive responses out of total 6 questions were considered as satisfactory investigation skills. The same $50 \%$ cutoff used for examination and history skills.

Statistical associations were performed using chi-square test for each skill separately with gender, designation and sciences. A p-value of 0.05 or less was considered statistically significant and 0.01 or less as highly significant.

By using PASS version 11 chi square test with $95 \%$ confidence interval, effect size of 0.2478 , df 2 and 0.1528 , df 1 for designation versus history taking skills and sciences 
versus examination skills calculated power of test is $98 \%$ and $77 \%$ respectively which is $80 \%$ around. This justifies our sample size of taking 315 participants. It is noted that power of test was computed only for significant factors.

\section{RESULT}

The response rate was $90.66 \%$.The mean age of participants was $23.4 \pm 3.68$ years \pm SD. Total 315 forms were analyzed. It included maximum undergraduate dental students 243 (77.1\%), followed by postgraduate trainees 39 $(12.3 \%)$ than faculty $33(10.5 \%)$. Table 01 reported that male was $66(21.0 \%)$ and female were $249(79.0 \%)$. The highest number of participants were from Department of Operative Dentistry $(n=67) 21.3 \%$ followed by Prosthodontics Department $(\mathrm{n}=51) 16.2 \%$, followed by other departments; Periodontology $(n=50) 15.9 \%$, Oral Surgery $(n=42) 13.3 \%$, Oral Medicine $(n=35) 11.1 \%$, Orthodontics $(n=29) 9.2 \%$, Community Dentistry $(n=24) 7.6 \%$, Oral Pathology $(n=10)$ $3.2 \%$, Oral Biology $(n=4) 1.3 \%$ and Dental Materials $(n=3)$
$1.0 \%$ in descending order. Most of the participants $(n=246)$ $78.1 \%$ answered that they always take complete medical history (that is termed as satisfactory HTS in our study) at first visit, $20.3 \%(n=64)$ responded that they often take complete history (also marked as satisfactory HTS) and $1.6 \%(n=5)$ reported that they rarely take complete medical history (marked as unsatisfactory HTS).

The history taking practice of medical conditions was carried out well in dental settings at DUHS as it was revealed that $(n=38) 92.7 \%$ basic sciences and $(n=237) 86.5 \%$ clinical sciences participants presented with satisfactory history taking skills (participants responded 'always' and 'often' to HTS question). There was no statistically significant difference observed in basic and clinical dental sciences HTS $(p=0.267)$. Majority of undergraduates $(n=205) 84.4 \%$, all of postgraduates $(n=39) 100 \%$ and majority faculty members (n=31) 93.3\% showed satisfactory skills of history taking. However, designation of dentists showed significant difference $(\mathrm{p}=0.012)$. (table no. 2$)$

Medical examination skills of basic sciences participants

Table 2: Association of Skills with Demographics

\begin{tabular}{|l|l|}
\hline Demographics & $\mathbf{N}(\mathbf{\%})$ \\
\hline Age (Mean \pm SD) & $23.4 \pm 3.68$ \\
\hline Gender & \\
\hline Male & $066(21.0 \%)$ \\
\hline Female & $249(79.0 \%)$ \\
\hline Basic Sciences & \\
\hline Oral Pathology & $10(3.2 \%)$ \\
\hline Oral Biology & $04(1.3 \%)$ \\
\hline Community Dentistry & $24(7.6 \%)$ \\
\hline Dental Materials & $03(1.0 \%)$ \\
\hline Clinical Sciences & \\
\hline Operative Dentistry & $67(21.3 \%)$ \\
\hline Periodontology & $50(15.9 \%)$ \\
\hline Oral Surgery & $42(13.3 \%)$ \\
\hline Orthodontics & $299(9.2 \%)$ \\
\hline Prosthodontics & $51(16.2 \%)$ \\
\hline Oral Medicine & $35(11.1 \%)$ \\
\hline Colleges & \\
\hline DIKIOHS & $154(48.9 \%)$ \\
\hline DIDC & $091(28.9 \%)$ \\
\hline DDC & $070(22.2 \%)$ \\
\hline Designation & \\
\hline Undergraduate & $243(77.1 \%)$ \\
\hline PG & $039(12.3 \%)$ \\
\hline Faculty & $033(10.5 \%)$ \\
\hline
\end{tabular}

\begin{tabular}{|c|c|c|c|c|}
\hline \multicolumn{2}{|c|}{ History taking Skills (HTS) } & Satisfactory & Unsatisfactory & P-value \\
\hline \multirow{2}{*}{ 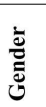 } & Male $(n=66)$ & $59(89.4 \%)$ & $07(10.6 \%)$ & \multirow{2}{*}{0.566} \\
\hline & Female $(n=249)$ & $216(86.7 \%)$ & $33(13.3 \%)$ & \\
\hline \multirow{2}{*}{ 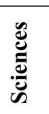 } & Basic $(n=66)$ & $38(92.7 \%)$ & $03(07.3 \%)$ & \multirow{2}{*}{0.267} \\
\hline & Clinical $(n=249)$ & $237(86.5 \%)$ & $37(13.5 \%)$ & \\
\hline \multirow{3}{*}{ 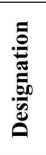 } & Undergraduate $(n=243)$ & $205(84.4 \%)$ & $38(15.6 \%)$ & \multirow{3}{*}{$0.012^{*}$} \\
\hline & Post graduate $(n=39)$ & $39(100.0 \%)$ & $0(0.0 \%)$ & \\
\hline & Faculty $(n=33)$ & $31(93.9 \%)$ & $2(06.1 \%)$ & \\
\hline \multicolumn{2}{|c|}{ Examination skills (ES) } & Satisfactory & Unsatisfactory & P-value \\
\hline \multirow{2}{*}{ 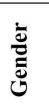 } & Male $(n=66)$ & $52(78.8 \%)$ & $14(21.2 \%)$ & \multirow{2}{*}{0.122} \\
\hline & Female $(n=249)$ & $172(69.1 \%)$ & $77(30.9 \%)$ & \\
\hline \multirow{2}{*}{ 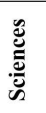 } & Basic $(n=66)$ & $24(58.5 \%)$ & $17(41.5 \%)$ & \multirow{2}{*}{0.057} \\
\hline & Clinical (n=249) & $200(73.0 \%)$ & $74(27.0 \%)$ & \\
\hline \multirow{3}{*}{ 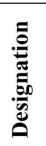 } & Undergraduate $(n=243)$ & $174(71.6 \%)$ & $69(28.4 \%)$ & \multirow{3}{*}{0.569} \\
\hline & Post graduate $(n=39)$ & $29(74.4 \%)$ & $10(25.6 \%)$ & \\
\hline & Faculty $(n=33)$ & $21(63.6 \%)$ & $12(36.4 \%)$ & \\
\hline \multicolumn{2}{|c|}{ Investigation skills (IS) } & Satisfactory & Unsatisfactory & P-value \\
\hline \multirow{2}{*}{ 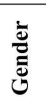 } & Male (n= 66) & $38(57.6 \%)$ & $28(42.4 \%)$ & \multirow{2}{*}{0.190} \\
\hline & Female $(n=249)$ & $165(66.3 \%)$ & $84(33.7 \%)$ & \\
\hline \multirow{2}{*}{ 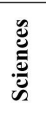 } & Basic $(n=66)$ & $24(58.5 \%)$ & $17(41.5 \%)$ & \multirow{2}{*}{0.397} \\
\hline & Clinical (n=249) & $179(65.3 \%)$ & $95(34.7 \%)$ & \\
\hline \multirow{3}{*}{ 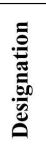 } & Undergraduate $(n=243)$ & $161(66.3 \%)$ & $82(33.7 \%)$ & \multirow{3}{*}{0.186} \\
\hline & Post graduate $(n=39)$ & $20(51.3 \%)$ & $19(48.7 \%)$ & \\
\hline & Faculty $(n=33)$ & $22(66.7 \%)$ & $11(33.3 \%)$ & \\
\hline
\end{tabular}


showed satisfactory result, $(\mathrm{n}=24) 58.5 \%$ participants examine patients thoroughly in respect of medical condition assessment. Whereas, $(n=200) 73.0 \%$ clinical sciences participants also showed satisfactory examination skills and there was no significant difference observed $(p=0.057)$. The majority undergraduates $(\mathrm{n}=174) 71.6 \%$, postgraduates $(n=29) 74.4 \%$ and faculty members $(n=21) 63.6 \%$ showed satisfactory examination skills. The p-value reported for designation was statistically non-significant (0.569).

The practice of lab investigation for systemic diseases was found satisfactory for undergraduates $(n=161) 66.3 \%$, postgraduates $(n=20) 51.3 \%$ and for faculty $(n=33) 66.7 \%$. furthermore, it was found satisfactory also for basic sciences $(n=24) 58.5 \%$ and clinical sciences (n-179) $65.3 \%$. There was no significant difference observed for dental sciences $(p=0.397)$ and designation of the dentists in context of advice for lab investigation $(\mathrm{p}=0.186)$.

\section{DISCUSSION}

Assessment of systemic diseases at chair side of dental patients is getting prominence in contemporary holistic medical and dental approach. ${ }^{9}$ The practice of dentist to recognize the insidious medical conditions reduces the latent period of disease. In our study, knowledge and skills related to chair-side assessment of medical conditions by dentists were evaluated and results revealed that dentists were well aware of and willing to conduct chair-side general health checks for dental patients. Post graduate students showed $100 \%$ satisfactory result in history taking skills (HTS) and faculty members also showed $93.9 \%$ satisfactory HTS, while undergraduate students showed $84.4 \%$ satisfactory HTS. The difference was statistically significant ( $\mathrm{p}$ value $=0.012$ ). This defines the importance of post graduate dental education that makes the dentist with broad sense of holistic approach in which he/she takes care not only the dental issues but also considering systemic health of patient's such as taking blood pressure and blood glucose level etc. as well. The results of our study are in contrast to study conducted by Shah et al. In that study the dentist showed undesirable results in history taking skills. ${ }^{10}$ The difference in result may be due to the sampling of dentist practicing in public and private sectors in Shah study, whereas, in our study participants were undergraduate and postgraduate students, house officers and faculty who are in continuous process of dental education in university environment.

Another study conducted in USA 2016, by Shimpi et al stated that majority of dentists believed in importance of performing chair-side screening for medical conditions in dental settings. ${ }^{11}$ In the same study $85 \%$ of United States dental care providers stated that more frequently evaluated medical condition in dental settings was hypertension. ${ }^{11}$ In our study's examination skills (ES), evaluation of hypertension by dentists was found satisfactory without any difference between variables. Hypertension was also the most frequently conducted ES of dentists in our study.

Dentist related to basic sciences showed $(58.5 \%)$ satisfactory result of examination skills (ES) while the dentist related to clinical sciences showed $(73.0 \%)$ satisfactory result. However, the difference is not significant $(p=0.057)$. This shows clinical practice makes dentist to consider the systemic disease evaluation more important along with dental problem as compare to the dentist who were related to basic sciences.

The investigation skills (IS) were measured by asking about what tests were advised for diabetes, hypertension, anemia, gout, arthritis, peptic ulcer and TB from suspected patients. Out of six questions three positive responses with diabetes and hypertension as compulsorily investigated diseases were considered satisfactory. The importance of patient's chronic diseases (above mentioned) information is crucial in prescribing medications for dental problem keeping in mind the possibility of gastric trouble caused by prolonged medicine intake for chronic diseases. There was no significant difference between the dentists of different gender or basic or clinical dental sciences or different designations in investigatory skills (IS). The average satisfactory IS was $61.71 \%$, therefore it may be a room for improvement by further raising the significance of lab investigation.

In our study, sampling was done on the basis of dental practitioner presence at the time of survey or presence of dental students in dental OPDs. The sample was collected from three colleges of same university; other dental universities could also be incorporated. In this study only practical skills of dental care professionals were measured.

\section{CONCLUSIONS}

It was concluded that practice of medical history taking, medical examination and lab investigations by dental professionals of DUHS was adequate. Dentist skills were not dependent on gender, designation and basic or clinical sciences.

\section{RECOMMENDATIONS}

These skills of dentists must be further improved to serve the patients with superior dental care considering in the light of overall health related issues of the patient. It is recommended to put more emphasis on medical history taking skills of dental undergraduates in DUHS. Such dental professional approach saves time and is cost effective. This 
approach also refers patients towards medical treatment of diseases which are a global health burden.

\section{CONFLICT OF INTEREST}

None declared.

\section{REFERENCES}

1. Laurence B. Dentists consider medical screening important and are willing to incorporate screening procedures into dental practice. J Evid Based Dent Pract. 2012 Sep;12 (3 Suppl):32-3.

https://doi.org/10.1016/S1532-3382(12)70008-8

2. Sansare K, Raghav M, Kasbe A, Karjodkar F, Sharma N, Gupta A, et al. Indian patients' attitudes towards chairside screening in a dental setting for medical conditions. Int Dent J. 2015;65(5):269-76. https://doi.org/10.1111/idj.12175

3. Greenberg BL, Glick M, Goodchild J, Duda PW, Conte NR, Conte M. Screening for cardiovascular risk factors in a dental setting. J Am Dent Assoc. 2007;138(6):798-804. https://doi.org/10.14219/jada.archive.2007.0268

4. Glick M, Greenberg BL. The potential role of dentists in identifying patients' risk of experiencing coronary heart disease events. J Am Dent Assoc. 2005;136(11):1541-6. https://doi.org/10.14219/jada.archive.2005.0084

5. Barasch A, Safford MM, Qvist V, Palmore R, Gesko D, Gilbert GH. Random blood glucose testing in dental practice:
A community-based feasibility study from The Dental Practice-Based Research Network. J Am Dent Assoc. 2012;143(3):262-9. https://doi.org/10.14219/jada.archive.2012.0151 6. Rey A, Thoenes M, Fimmers R, Meier CA, Bramlage P. Diabetes prevalence and metabolic risk profile in an unselected population visiting pharmacies in Switzerland. Vasc Health Risk Manag. 2012;8:541.

7. Genco RJ, Schifferle RE, Dunford RG, Falkner KL, Hsu WC, Balukjian J. Screening for diabetes mellitus in dental practices: a field trial. J Am Dent Assoc. 2014;145(1): 57-64.

https://doi.org/10.14219/jada.2013.7

8. Greenberg BL, Glick M, Frantsve-Hawley J, Kantor ML. Dentists' attitudes toward chairside screening for medical conditions. J Am Dent Assoc. 2010 Jan;141(1):52-62. https://doi.org/10.14219/jada.archive.2010.0021

9. Creanor S, Millward B, Demaine A, Price L, Smith W, Brown N, et al. Patients' attitudes towards screening for diabetes and other medical conditions in the dental setting. Br Dent J. 2014;216(1):E2-E.

10. Shah I, Luqman U, Fayaz M, Ibrahim M, Babar A. Inadequacies in history taking and clinical examination by the dentists. Pak Oral Dent J. 2009;29(2):211-14.

11. Shimpi N, Schroeder D, Kilsdonk J, Chyou P, Glurich I. Assessment of Dental Providers' Knowledge, Behavior and Attitude towards Incorporating Chairside Screening for Medical Conditions: a pilot study. J Den Oral Care Med. 2016;2(1):102. 